\title{
2 cases dysgerminoma with micrometastasis in lymph nodes
}

\author{
Valdespino VE*, Montenegro YB, Hernandjez MR, Cordova GM, Mejia JL and Gomez VV \\ Gynecological and obstetrician hospital, "Luis Castelazo Ayala" Mexico City, Mexico
}

\begin{abstract}
We reported 2 cases of micrometastasis in dysgerminoma, specify incidence of micrometastasis is unknown. Many times when micrometastasis is reported, the variability is constant, those are reported in nodal sentinel dissection, or systematic lymphadenectomy, or with immunohistochemistry. We use the definition of micrometastasis agree with AJCC. (American Joint Committee on Cancer). We show 2 patients with retroperitoneal nodal micrometastasis and dysgerminoma; omentectomy, cytology, was performed and this resulted negative to metastasis. They received chemotherapy (4 times BEP) with good tolerance; both are alive without symptoms. We encourage sparing surgery for endocrinal and reproductive function always. Nowadays micrometastasis is an advice to adjuvant treatment, but maybe with more reports, we can improve ower medical care, perhaps target therapy, vigilance or use a low dose of chemotherapy. We need more reports on this subject. Ower oncology gynecology group stimulate systematic pelvic and paraaortic lymphadenectomy or sentinel node dissection in dysgerminoma. With all prognostic factors we can tailor adjuvant treatment in germinative tumors. In the future maybe lymph node ratio, or new classification on nodal metastasis by FIGO (International Federation of Gynecology and Obstetrics) or AJCC, could improve ower knowledge on the biological behavior of micrometastasis.
\end{abstract}

\section{Introduction}

Ovarian dysgerminomas are infrequent and account for only about $2 \%$ of all malignant ovarian neoplasm [1]. They are female analogous to male seminoma and most commonly arise in adolescents and young women [2]. Seventy-five percent of women with dysgerminoma present with stage I at diagnosis and bilateral ovarian involvement occur in 10 $15 \%$ [3]. Lymph node metastasis found in $28 \%$ of patients with ovarian dysgerminoma and was an independent predictor of poor survival [4]. On germinal ovarian cancer, dysgerminoma is most frequently relately with nodal metastasis.

Dysgerminoma appears similar to; $80 \%$ to $90 \%$ are unilateral and grossly appear as tan-colored, lobulated, firm mass. It is composed of undifferentiated germ cells and large vesicular cells dispersed in sheets or cords interspersed by scant fibrous stroma, with a variable degree of atypia. Mature lymphocytes and occasional granulomas infiltrate the fibrous stroma. These malignant cells usually express CD117, OCT3, and OCT4 [5].

More than germinative malignant tumors $90 \%$ developed in gonads, and $10 \%$ are extragonadal, they are growing in retroperitoneal, mediastinal or central nervous system [6].

Dysgerminoma has an excellent response to chemotherapy, those that have extended beyond the ovary can often be cured, with overall survival of greater than $80 \%$. In treating dysgerminoma, surgery is not only therapeutic but also required for diagnosis and staging, with a scope of procedure dependent on intraoperative findings and patient's desire whether or not she wants to maintain fertility or avoid exogenous estrogen $[7,8]$.

Ovarian dysgerminoma is highly sensitive to platinum-based chemotherapy $[9,10]$. Adjuvant chemotherapy was associated with significant improvement in DFS (disease free survival) (HR, 0.09; $95 \% \mathrm{CI}, 0.01-0.84 ; \mathrm{P}=0.034)$. The benefit and the risk of aggressive cytoreductive surgery for metastatic disease must be carefully weighed for this tumor. Even leaving residual disease after cytoreductive surgery in patients with advanced stage, they will have a long-term outcome with modern cisplatin-based adjuvant chemotherapy [10,11].

\section{Cases}

In ower hospital, micrometastasis is establish like a cluster from 0.2 $\mathrm{mm}$ to $2 \mathrm{~mm}$ malignant cells in nodal metastasis [12]. We systematicaly performed lymphadenectomy paraaortic and pelvic in ovarian cancer or nodal sentinel biopsy with blue dye (and standing surgery). We show 2 cases with micrometastasis in a services of gynecology oncology.

\section{Case 1}

Female patient 22 years old, no cancer family history, bachelor scholarship, no surgeries, no chronic disease. No pregnancy, no contraceptive method. She beginning 6 months before to the first appointment in gynecology oncology, with abdominal perimeter growing and menstrual bleeding pain. Laboratories result Ca125 117, AFP 0.99; DHL 889. Ultrasound with tumor irregular 23.6 x 19.7 x 19.1 $\mathrm{cm}$.

We performed a surgery with transoperatory evaluation of tumor. The result was dysgerminoma; we used blue dye with retroperitoneal sentinel node dissection. Dysgerminoma with micrometastasis in retroperitoneal node dissection, one node with micrometastasis, 16 retroperitoneal nodes were the total resected, and 14 pelvis nodes without metastases.

${ }^{\star}$ Correspondence to: Valdespino VE, Gynecological and obstetrician hospital, "Luis Castelazo Ayala”, Mexico, Tel: +525573678619; E-mail: edvaldespinocg@yahoo.com

Key words: micrometastais, dysgerminoma, nodal retroperitoneal metastasis

Received: December 05, 2018; Accepted: December 20, 2018; Published: January 05, 2019 


\section{Case 2}

Female patient 26 years old, a grandmother with colon cancer, bachelor not ended, the patient do not specify a time, no pregnancy story, no anticoncpetion method. She develope cronic abdominal pain 4-5 months before to get medical attention, medical exploration shows us a tumor $10 \mathrm{~cm}$ in pelvis-abdomen. Ultrasound reported ovarian tumor $97 \times 77 \mathrm{~mm}$, mixted but solid in the mayority. Laboratoris result DHL 1049, betaHGC 18. Transoperatory reported dysgerminoma, on tumor; transoperatory sentinel nodal disecction, do not report tumor (with blue dye) but in definitive result 1 nodal with micrometastasis. Also, pathologyst reporte 19 retroperitoneal nodal without metastases and 15 pelvic nodes without metastases.

We are in a step of validation on sentinel node disection. We used to send the sentinel nodal metastasis to transoperatory (and the pathologist give us a preliminar result) and 20 days later, pathologyst report definitive, in both cases micrometastasis in one node. Also reported no metastasis in omentum. Ovarian tumor were in both cases dysgerminoma.

Pathology deparment cut 7 or 8 times each sentinel nodal; in a systematic lymphadenectomy just 1 time nodal is assess.

Both patients receive BEP bleomycin, etoposide and cisplatin 4 times, with good tolerance, they are alive without syntoms 24 months and 39 months, respectively (Figures 1-4).

\section{Discussion}

The main treatment for dysgerminoma includes surgery, and chemotherapy with optimal cytoreduction. The majority of patients (76.9\%) in Husani's report underwent fertility-sparing surgery, and 44 (67.7\%) received postoperative chemotherapy or radiotherapy. Only eight (12.3\%) patients underwent complete surgical staging including omentectomy, cytology, and lymph node sampling/dissection [13]. Like Husaini ower oncology gynecology service encourage the fertilitysparing surgery but, systematically standing surgery is performed always: omentectomy, cytology, salpingo-oophorectomy and nodal evaluation with sentinel nodal dye and or systematic lymphadenectomy retroperitoneal and pelvic [14].

The germinates ovary tumors in our services, receives standing comprehensive surgery, in a different treatmetment than Vicus report,

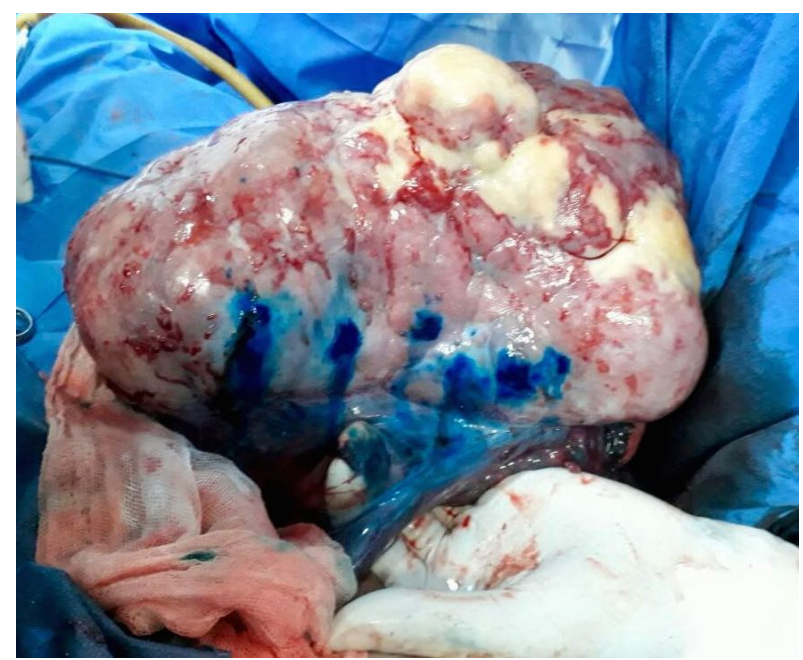

Figure 1. Blue dye in transoperatory, ovary tumor before to resection

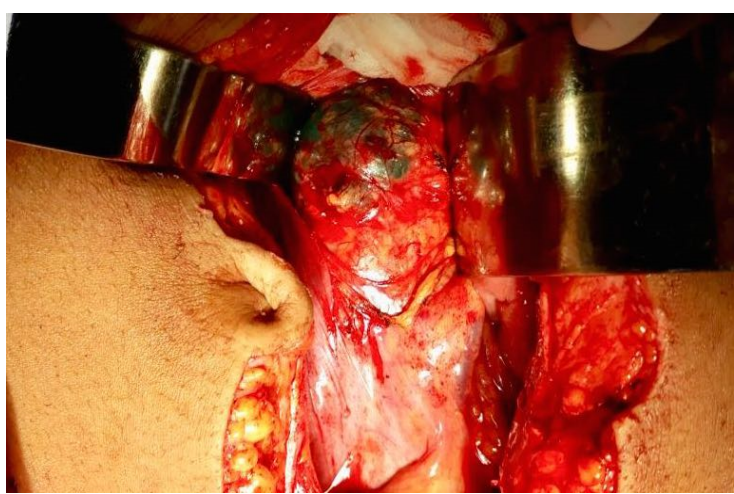

Figure 2. Retroperitoneal open and and blue dye in paraaortic nodal

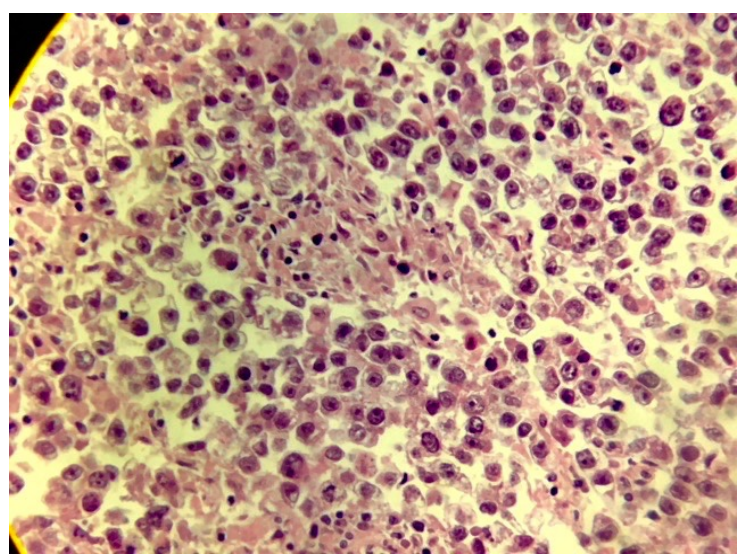

Figure 3. Micrometastasis in retroperitoneal lymph node, case 1

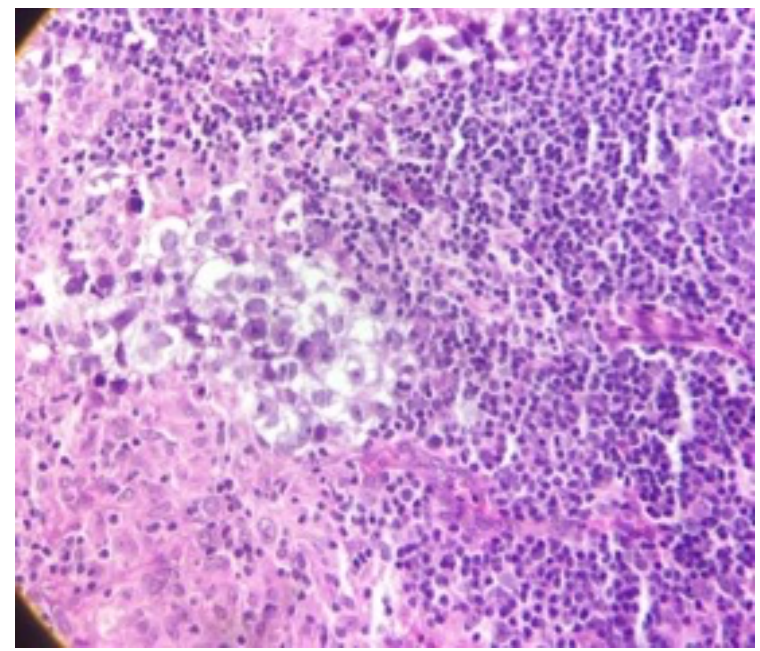

Figure 4. metastastasis nest with light cytoplasma, promient nucleoli, and central nucleus, case 2

they do not perform the systematic standing in his report they only performed 4 standing operations [15].

Sentinel lymph node dissection is becoming increasingly popular in the management of gynecologic cancers.

In general, many autors classify lymph nodes involved with metastasis one of 3 categories based on the size of metastasis; ITC (isolated tumoral cells), $0.2 \mathrm{~mm}$, micrometastasis, $0.2-2 \mathrm{~mm}$ and macrometastasis, $2 \mathrm{~mm}$ [12]. 
Regardless of our enhanced ability to detect nodal micrometastasis, the impact of their presence on prognosis remains unclear [3]. Probably the 9th edition of the AJCC staging manual will contain definitive data on this important subject (nodal micrometastasis) [16].

Low volume metastasis by producing VEGF (vascular endothelial growth factor) and other proangiogenic molecules, residual tumor cells can induce an "angiogenic switch" in avascular micrometastases that is necessary to convert them into macrometastases. Micrometastases might perhaps be more sensitive to VEGF depletion than large metastases, where VEGF is only one of the multiple factors perpetuating tumor angiogenesis. Anti-VEGF treatment could block tumor dissemination and inhibit the early growth of micrometastatic. This affirmation could be a normal treatment, but we need more clinical trials on micrometastasis [17].

First nodal level for ovarian metastasis is the retroperitoneal area, (paraaortic) when we practice the nodal sentinel dissection, always wait how many nodes dye and performed the resection, we can avoid the systematic dissection or continued with it. We send to transoperative evaluation and finished the surgery or continue systematic lymphadenectomy (we are in a process to validation).

We encourage the comprehensive surgery or sentinel node dissection in germinative ovarian cancer particularly in dysgerminoma, because only in this way that we can know all prognostic factors on primary cancer, nodal metastasis; and sometimes we can avoid chemotherapy and radiotherapy and those toxic effects on patients. The systematic retroperitoneal lymphadenectomy can remove micrometastasis or in those cases give us a positive chemotherapy indication treatment.

Micrometastasis most of the times are reported in a context of sentinel nodal dissection, but Suzuki and coworkers reported like us in comprehensive surgery but they used immunohistochemical staining. Reports of micrometastasis in ovarian cancer conditioned an adjuvant treatment [18].

We let is the question open, and maybe in the future, we can answer, with many reports on micrometastasis in ovarian cancer. Nowadays if a patient has nodal metastases, they need chemotherapy in dysgerminoma [19]; but, if the patients have a systematic retroperitoneal and pelvic lymphadenectomy and comprehensive standing surgery or a sentinel nodal biopsy validate, with negative to macrometastastasis only micrometastasis, the patients do not need adjuvant treatment? In ower current surgical practice, we performed systematically lymphadenectomy pelvic and retroperitoneal or nodal sentinel biopsy with blue dye, in ovarian cancer, in dysgerminoma [14].

Dysgerminoma is the tumor with more likely to develop nodal metastases we perform and recommended, comprehensive surgical cytoreduction with sparing uterus and ovary or partial ovary, omentectomy, retroperitoneal sentinel dissection and or lymphadenectomy paraaortic and pelvic.

Furthermore, we do not agree when a patient is affected by a bilateral ovarian disease, we try to perform a sparing fertility surgery, Zogby and coworkers do not preserve ovary and uterine corp, and the uterus and just partial contralateral ovary were affected by the tumor $[19,20]$. Always we propose to preserve the reproductive and endocrinal function.

Most of the times dysgerminoma grow slowly, but rarely needs emergency surgery by torsión [21]. Torsion of ovarian tumors mostly occurred in the reproductive age group, more commonly on the right side, and only approximately $8 \%$ of masses were malignant [22].

The incidence of micrometastasis in dysgerminoma is not specify. We need more reports on micrometastasis and ovarian cancer and review overall survival. What is behavior with metachronous micrometastasis or associated with tumoral cells isolated, or synchronic metastasis, those questions do not have answer by this moment. We need more experience and reports on micrometastasis.

\section{References}

1. Thomas GM, Dembo AJ, Hacker NF, DePetrillo AD (1987) Current therapy for dysgerminoma of the ovary. Obstet Gynecol 70: 268-275. [Crossref]

2. De Palo G, Pilotti S, Kenda R, Ratti E, Musumeci R, et al. (1982) Natural history of dysgerminoma. Am J Obstet Gynecol 143: 799-807. [Crossref]

3. Kumar S, Shah JP, Bryant CS, Imudia AN, Cote ML, et al. (2008) The prevalence and prognostic impact of lymph node metastasis in malignant germ cell tumors of the ovary. Gynecol Oncol 110: 125-132. [Crossref]

4. Chatchotikawong U, Ruengkhachorn I, Leelaphatanadit C, Phithakwatchara N (2015) 8-year Analysis of the Prevalence of Lymph Nodes Metastasis, Oncologic and Pregnancy Outcomes in Apparent Early-Stage Malignant Ovarian Germ Cell Tumors. Asian Pac J Cancer Prev 26: 1609-1613. [Crossref]

5. Ajao M, Vachon T, Snyder P (2013) Ovarian dysgerminoma: a case report and literature review. Mil Med 178: e954-955. [Crossref]

6. Ocal N, Yildiz B, Karadurmus N, Dogan D, Ozaydin S, et al. (2016) Comparison of the clinical features and hematopoietic stem cell transplantation outcomes of mediastinal malignant germ cell tumors with nonmediastinal extragonadal placements. Onco Targets Ther 9: 7445-7450. [Crossref]

7. Mangili G, Sigismondi C, Lorusso D, Cormio G, Scollo P, Vigano R, Gamucci T, Candiani M, Pignata $S$ (2011) Is surgical restaging indicated in apparent stage IA pure ovarian dysgerminoma? The MITO group retrospective experience. Gynecol Oncol 121: 280-284. [Crossref]

8. Gershenson DM, Miller AM, Champion VL, Monahan PO, Zhao Q, et al (2007) Reproductive and sexual function after platinum-based chemotherapy in long-term ovarian germ cell tumor survivors: a Gynecologic Oncology Group Study. J Clin Oncol 25: 2792. [Crossref]

9. Gershenson DM, Morris M, Cangir A, Kavanagh JJ, Stringer CA, et al. (1990) Treatment of malignant germ cell tumors of the ovary with bleomycin, etoposide, and cisplatin. J Clin Oncol 8: 715-720. [Crossref]

10. Culine S, Lhomme C, Kattan J, Michel G, Duvillard P, et al. (1997) Cisplatin-based chemotherapy in the management of germ cell tumors of the ovary: The Institut Gustave Roussy Experience. Gynecol Oncol 64: 160-165. [Crossref]

11. Dimopoulos MA, Papadopoulou M, Andreopoulou E, Papadimitriou C, Pavlidis N, et al. (1998) Favorable outcome of ovarian germ cell malignancies treated with cisplatin or carboplatin-based chemotherapy: a Hellenic Cooperative Oncology Group study. Gynecol Oncol 70: 70-74. [Crossref]

12. Edge S, Byrd D, Compton C, Eds. Fritz A (2010) AJCC Cancer Staging Manual; 7th ed Philadelphia: Lippincott Raven.

13. Husaini H, Soudy H, Darwish A, Ahmed M, Eltigani A, et al. (2012) Pure dysgerminoma of the ovary: a single institutional experience of 65 patients. Med Oncol 29: 2944-2948. [Crossref]

14. Valdespino V, Maytorena G, Valdespino V, Olguin V, Zeferino M, et al. (2018) Retroperitoneal nodal dissection in gynecological cancer: utility as a predictive biomarker. Gynecol Obstet Mex 2018: 464-477.

15. Vicus D, Bainer M, Klachook S, Le L, Lafamboise S, et al. (2010) Pure dysgerminoma of the ovary 35 year on: A single institutional experience. Gynecol Oncol 117: 23-26. [Crossref]

16. Olawaiye A, Mutch D (2018) Lymph node staging update in the American Joint Committee on Cancer 8th Edition cancer staging manual. Gynecol Oncol 150: 7-8. [Crossref]

17. Le Guelte A, Dwyer J, Gavard J (2011) Jumping the barrier: VE-cadherin, VEGF and other angiogenic modifiers in cancer. Biol Cell 103: 593-605. [Crossref]

18. Suzuki M, Ohwada M, Saga Y, Kohno T, Takei Y, et al. (2001) Micrometastatic p53positive cells in the lymph nodes of early-stage epithelial ovarian cancer: prognostic significance. Oncology 60: 170-175. [Crossref] 
19. Ray-Coquard I, Morice P, Lorusso D, Prat J, Oaknin A, et al. (2018) Non-epithelial ovarian cancer: ESMO Clinical Practice Guidelines for diagnosis, treatment and follow-up. Ann Oncol 29: iv1-iv18. [Crossref]

20. Zogbi L, Gonçalves CV, Tejada VF, Martins D, Karam F, et al. (2018) Treatment of bilateral ovarian dysgerminoma with 11-year follow-up: A case report. Ann Med Surg (Lond) 33: 50-52. [Crossref]
21. Khandwala K, Shahid J, Nadeem N, Tariq MUU (2018) Torsion of Ovarian Dysgerminoma in a Child: Role of Computed Tomography. Cureus 10: e2522. [Crossref]

22. Lee CH, Raman S, Sivanesaratnam V (1989) Torsion of ovarian tumors: a clinicopathological study. Int J Gynaecol Obstet 28: 21-25. [Crossref]

Copyright: C2019 Valdespino VE. This is an open-access article distributed under the terms of the Creative Commons Attribution License, which permits unrestricted use, distribution, and reproduction in any medium, provided the original author and source are credited. 